\title{
Emerging spectrometric techniques for the forensic analysis of body fluids
}

Félix Zapata, Ma Ángeles Fernández de la Ossa, Carmen García-Ruiz*

Department of Analytical Chemistry, Physical Chemistry and Chemical Engineering and University Institute of Research in Police Sciences (IUICP), University of Alcalá, Ctra. Madrid-Barcelona km 33.600, 28871 Alcalá de Henares (Madrid), Spain.

Email: carmen.gruiz@uah.es; felix.zapata@uah.es

Cite: F. Zapata, M. A. Fernández de la Ossa, C. García-Ruiz, Emerging spectrometric techniques for the forensic analysis of body fluids, TrAC 64 (2015) 53-63. DOI: $\underline{\text { 10.1016/j.trac.2014.08.011 }}$ 


\begin{abstract}
Body fluids are evidence of great interest in forensics because they allow identification of individuals through the study of DNA. After reviewing the tests and the methods that are currently being used by forensic practitioners for the detection of body fluids (e.g. blood, semen, saliva, vaginal fluid, urine and sweat), and after showing their main drawbacks and limitations, this work focuses on the review of emerging spectrometric techniques applied for the forensic analysis of body fluids. These techniques include the use of ultraviolet-visible, infrared (IR), Raman, X-ray fluorescence and nuclear magnetic resonance spectroscopy and mass spectrometry for investigating blood, semen, saliva, urine, vaginal fluid or sweat. Although all these spectrometric techniques seem to have a high potential to differentiate body fluids prior to DNA extraction, IR and Raman spectroscopy have shown the most promising results for discriminating stains from body fluids.
\end{abstract}

Keywords: Body fluids; Blood; Semen; Spectrometric techniques. 


\section{Introduction}

Body fluids are exceptionally useful forensic evidence because they provide information that allows police to discover their corresponding owner by analysing the DNA (deoxyribonucleic acid) content. Since DNA testing has acquired huge relevance for solving crimes, the detection of biological evidence at the crime scene has become one of the priorities of law-enforcement officers during ocular inspection. According to Locard's principle, "every contact leaves a trace", so a small part of the offender usually stays in the place while a small part of the place goes with the offender (e.g. in homicide, resulting from confrontation between victim and aggressor, residues from the victim are probably found on the attacker and vice versa) [1]. After trace detection, the forensic process continues with evidence analysis to obtain information about the source (identity) or activity (why the trace is where it is) and how it might relate to a proposed crime scene.

Technically, a biological fluid comes from a living being. In the forensic field, the biological fluids of interest are body fluids, which come from a human being, especially those from the attacker. Body fluids generated by human beings include blood, semen, saliva, vaginal fluid, urine, sweat, breast milk, tears and mucus. Undoubtedly, blood, semen and saliva are found in larger amounts than the others at crime scenes, and thus, they have been the most studied [2-4].

Tests currently used to analyse body fluids are classified according to their specificity in two different categories (presumptive and confirmatory) [2]. Presumptive tests provide a large number of false positives (i.e. the test is positive although the body fluid is not present in the sample). Presumptive tests are unspecific to a single body fluid, so a positive response is due only to the suspicion that the fluid may be present in the stain. Thus, it is always necessary to apply a confirmatory test to confirm the presence of a body fluid in a stain because, by contrast, confirmatory tests are specific to identify a particular body fluid. A positive response certainly ensures the presence of the searched body fluid in the stain under examination.

Presumptive and mainly confirmatory tests used in body-fluid identification are based on each body fluid having a unique composition, which is the result of specific components of each body fluid and the difference in the relative ratio of common components found in several body fluids [2]. As Lednev and Virkler indicate [2], urea is 
found in urine, semen and sweat, its concentration in urine being larger than in either of the other two fluids. Table 1 shows the principal components present in blood, semen, saliva, vaginal fluid, urine and sweat [2].

Table 1. Major components of body fluids. Adapted from [2].

\begin{tabular}{llllll}
\hline Blood & Semen & Saliva & Vaginal fluid & Urine & Sweat \\
\hline Haemoglobin & Acid phosphatase & Amylase & Acid phosphatase & Urea & Chloride \\
Fibrinogen & Prostate-specific antigen & Lysozyme & Lactic acid & Creatinine & Sodium \\
Erythrocytes & Spermatozoa & Mucin & Citric acid & Uric acid & Urea \\
& Choline & & Urea & & \\
& Spermine & & Vaginal peptidase & & \\
& Semenogelin & & & & \\
& Urea & & & & \\
\hline
\end{tabular}

Table 2 shows the most relevant tests currently used to detect or to confirm blood, semen, saliva, vaginal fluid, urine and sweat. The columns indicate, respectively, test name, type of test (chemical, spectroscopic, microscopic, crystal test, immunological, chromatographic or electrophoretic), specificity (presumptive or confirmatory), main characteristics of the test and references. All the tests pursue the detection of specific components, ratios of components or characteristics, such as fluorescence, to detect presumptively or to confirm (identify) each body fluid.

Table 2. Current tests for identification of body fluids.

\begin{tabular}{|c|c|c|c|c|}
\hline Test & Type & Specificity & Characteristics & Ref. \\
\hline \multicolumn{5}{|l|}{ Blood } \\
\hline Luminol & Chemical & Presumptive & $\begin{array}{l}\text { Luminol added together with an oxidant }\left(\mathrm{H}_{2} \mathrm{O}_{2}\right) \text { becomes luminescent } \\
\text { in the presence of haemoglobin. }\end{array}$ & {$[2-4]$} \\
\hline Kastle-Meyer & Chemical & Presumptive & $\begin{array}{l}\text { Phenolphthalein (colourless), with } \mathrm{H}_{2} \mathrm{O}_{2} \text { added is oxidized to a pink } \\
\text { compound in the presence of haemoglobin }\end{array}$ & {$[2-4]$} \\
\hline $\begin{array}{l}\text { Leucomalachite } \\
\text { green }\end{array}$ & Chemical & Presumptive & $\begin{array}{l}\text { Leucomalachite green (colourless) is oxidized to a green compound in } \\
\text { the presence of haemoglobin }\end{array}$ & {$[2-4]$} \\
\hline Benzidine & Chemical & Presumptive & $\begin{array}{l}\text { Benzidine (white) is oxidized in EtOH/HAc medium to a blue } \\
\text { compound in the presence of haemoglobin }\end{array}$ & {$[2,4]$} \\
\hline Fluorescein & Chemical & Presumptive & $\begin{array}{l}\text { Fluorescin is oxidized to fluorescein in the presence of } \mathrm{H}_{2} \mathrm{O}_{2} \text { and } \\
\text { haemoglobin that fluoresces under UV light }\end{array}$ & [2] \\
\hline $\begin{array}{l}\text { Alternate light } \\
\text { sources (ALS) }\end{array}$ & Spectroscopic & Presumptive & Hematoporphyrin fluoresces under UV-Vis radiation & [2] \\
\hline $\begin{array}{l}\text { Microscopic } \\
\text { visualization }\end{array}$ & Microscopic & Confirmatory & Microscopic visualization of blood cells, white blood cells and fibrin & [2] \\
\hline $\begin{array}{c}\text { Takayama } \\
\text { crystals }\end{array}$ & Crystal test & Confirmatory & $\begin{array}{l}\text { Fe presents in haemoglobin reacts with pyridine producing pyridine } \\
\text { ferroprotoporphyrin (red crystals) }\end{array}$ & {$[2,4]$} \\
\hline $\begin{array}{l}\text { Teichman } \\
\text { crystals }\end{array}$ & Crystal test & Confirmatory & Haemoglobin reacts with halides producing hematin (brown crystals) & [2] \\
\hline $\begin{array}{l}\text { UV-Vis } \\
\text { Absorption }\end{array}$ & Spectroscopic & Confirmatory & $\begin{array}{l}\text { Soret band absorption at } 413 \mathrm{~nm} \text { characteristic of the presence of } \\
\text { blood }\end{array}$ & [2] \\
\hline Antibodies & Immunological & Confirmatory & $\begin{array}{l}\text { Enzyme-antibody specific interaction (precipitin test, ABACard, } \\
\text { HemaTrace, Ouchterlony, LDH, Hexagon Obti) }\end{array}$ & {$[2-4]$} \\
\hline
\end{tabular}




\begin{tabular}{|ccclc|c|}
\hline Semen & & & & \\
\hline $\begin{array}{c}\text { Alternate light } \\
\text { sources (ALS) }\end{array}$ & Spectroscopic & Presumptive & Semen fluoresces under UV-Vis radiation & {$[2,4]$} \\
\hline $\begin{array}{c}\text { Acid } \\
\text { phosphatase }\end{array}$ & Chemical & Presumptive & $\begin{array}{l}\text { Phosphatase catalyzes the hydrolysis of organophosphates which react } \\
\text { with a diazonium salt producing a coloured compound }\end{array}$ & {$[2-4]$} \\
\hline Florence & Crystal test & Presumptive & Choline produces brown crystals in the presence of potassium iodide & {$[2]$} \\
\hline Choline & Chemical & Presumptive & $\begin{array}{l}\text { Choline reacts with luminol analogously to blood (Choline oxidase- } \\
\text { luminol) }\end{array}$ \\
\hline Barberio & Crystal test & Presumptive & Spermine reacts with picric acid producing yellow crystals & {$[2]$} \\
\hline Spermine & Chromatographic & Presumptive & Spermine determined by HPLC & {$[2]$} \\
\hline SEM-EDX & Spectroscopic & Presumptive & Elemental analysis of semen (Na, P, S, Cl, K, Ca, etc.) by SEM-EDX \\
\hline $\begin{array}{c}\text { Microscopic } \\
\text { visualization- } \\
\text { Christmas tree }\end{array}$ & Microscopic & Confirmatory & $\begin{array}{l}\text { Visualizing spermatozoids under the microscope. Two reagents are } \\
\text { used to facilitate its observation turning tails-green and heads-red }\end{array}$ & {$[2,4]$} \\
\hline $\begin{array}{c}\text { Prostate } \\
\text { specific antigen } \\
\text { PSA) or P30 }\end{array}$ & Immunological & Confirmatory & $\begin{array}{l}\text { Specific interaction of PSA with its antibody (immunoelectrophoresis, } \\
\text { ELISA, Biosign PSA, ABACard) }\end{array}$ \\
\hline $\begin{array}{c}\text { Other } \\
\text { Antibodies }\end{array}$ & Immunological & Confirmatory & $\begin{array}{l}\text { Specific interaction of antibodies with antigens (Inmunoglobulin G1, } \\
\text { semenogelin, prostaglandin, LDH-X, } \gamma \text {-glutamyl transpeptidase) }\end{array}$ \\
\hline$[2,4]$ \\
\hline
\end{tabular}

\begin{tabular}{|c|c|c|c|c|}
\hline Saliva & & & & \\
\hline $\begin{array}{l}\text { Alternate light } \\
\text { sources (ALS) }\end{array}$ & Spectroscopic & Presumptive & Saliva fluoresces under UV-Vis radiation & {$[2,4]$} \\
\hline Amylase & Chemical & Presumptive & $\begin{array}{l}\text { Amylase catalyzes the hydrolysis of starch by which the solution } \\
\text { remains colourless when adding iodine (Starch-Iodine, Phadebas, } \\
\text { Rapignost-Amylase) }\end{array}$ & {$[2-4]$} \\
\hline SEM-EDX & Spectroscopic & Presumptive & Elemental analysis of saliva ( $\mathrm{Na}, \mathrm{P}, \mathrm{S}, \mathrm{Cl}, \mathrm{K}$, Ca, etc.) by SEM-EDX & [2] \\
\hline \multicolumn{5}{|l|}{ Vaginal fluid } \\
\hline $\begin{array}{l}\text { Periodic acid } \\
\text { Schiff }\end{array}$ & Chemical & Presumptive & $\begin{array}{l}\text { This reagent interacts with the cytoplasm of Glycogenated epithelial } \\
\text { cells producing a magenta colour }\end{array}$ & [2] \\
\hline $\begin{array}{c}\text { Vaginal } \\
\text { peptidase }\end{array}$ & Electrophoretic & Presumptive & $\begin{array}{l}\text { Enzyme that hydrolyzes the valine-leucine dipeptide. Reaction is } \\
\text { checked by gel electrophoresis }\end{array}$ & [2] \\
\hline $\begin{array}{l}\text { Oestrogen } \\
\text { receptors }\end{array}$ & Immunological & Presumptive & Specific interaction between oestrogen and antibody (17 $\beta$-estradiol) & [2] \\
\hline $\begin{array}{l}\text { Lactate/citrate } \\
\text { ratio }\end{array}$ & Electrophoretic & Presumptive & Lactate/citrate ratio measured by capillary isotachophoresis & [2] \\
\hline
\end{tabular}

\begin{tabular}{|c|c|c|c|c|}
\hline Urine & & & & \\
\hline $\begin{array}{l}\text { Alternate light } \\
\text { sources (ALS) }\end{array}$ & Spectroscopic & Presumptive & Urine fluoresces under UV-Vis radiation & [2] \\
\hline Urea & Chemical & Presumptive & $\begin{array}{l}\text { Urea is transformed into } \mathrm{NH}_{3} \text { and } \mathrm{CO}_{2} \text { by urease. Different reagents } \\
\text { (Nessler reagent, DMAC, bromothymol blue) }\end{array}$ & [2] \\
\hline Jaffe & Chemical & Presumptive & Creatinine reacts with picric acid producing a red precipitate & [2] \\
\hline Salkowski & Chemical & Presumptive & $\begin{array}{l}\text { Creatinine reacts with sodium nitroprusside producing a blue } \\
\text { compound }\end{array}$ & [2] \\
\hline $\begin{array}{l}\text { Tamm-Horsfall } \\
\text { (THP) }\end{array}$ & Immunological & Presumptive & Specific interaction of the glycoprotein THP and its antibody & [2] \\
\hline $\begin{array}{l}\text { Ureic acid/urea } \\
\text { ratio }\end{array}$ & Chemical & Presumptive & $\begin{array}{l}\text { Determination of human urine by measuring the urea/ureic acid ratio. } \\
\text { Different reagents (uricase-peroxidase, urease-indophenol) }\end{array}$ & [2] \\
\hline SEM-EDX & Spectroscopic & Presumptive & Elemental analysis of urine $(\mathrm{Na}, \mathrm{P}, \mathrm{S}, \mathrm{Cl}, \mathrm{K}, \mathrm{Ca}$, etc.) by SEM-EDX & [2] \\
\hline 17-Ketosteroid & Chromatographic & Presumptive & Identification of this steroid by HPLC-MS & [2] \\
\hline \multicolumn{5}{|l|}{ Sweat } \\
\hline SEM-EDX & Spectroscopic & Presumptive & Elemental analysis of sweat $(\mathrm{Na}, \mathrm{P}, \mathrm{S}, \mathrm{Cl}, \mathrm{K}$, Ca, etc.) by SEM-EDX & [2] \\
\hline
\end{tabular}


As seen in Table 2, the six body fluids can be presumptively detected by different tests, most of them chemical. However, there are available confirmatory tests solely for blood and semen, which involve immunological interactions, microscopic visualization of specific components or formation of specific crystals by chemical reaction. In addition to the lack of confirmatory tests for saliva, vaginal fluid, urine and sweat, there are other disadvantages, such as:

(1) most confirmatory tests (for blood and semen) are destructive; and,

(2) it is necessary to apply different tests to confirm each type of body fluid; this limitation requires division of a sample into several parts, and a portion of the sample having to be kept for possible future analyses.

To date, there is no test or method used by forensic practitioners able to detect and to confirm a body-fluid source without destroying the evidence [2, 5]. This situation makes it necessary to develop confirmatory non-destructive methods applicable to different types of body fluids. Nowadays, there are two principal lines of active research in body-fluid identification. One is dedicated to the development of mRNA (messenger ribonucleic acid) markers [6-12] based on the different mRNA sequences in each body fluid. The other is based on the use of spectrometric analytical techniques.

In this chapter, our goal is to provide a critical review of the works using emerging spectrometric techniques to analyse body fluids.

\section{Emerging spectrometric techniques}

Several analytical techniques can be applied to determine the presence in a stain of any of the different types of body fluid included in this review article.

In general, classical analytical chemistry is based on colorimetric assays, the use of many reagents and implementation of a large number of methods, usually specific for only one single analyte. As consequence it leaves room for spectrometric methodologies that are characterized by speed, and absence, or minimum use, of reagents and frequently applicable to the analysis of many analytes at a time. Spectrometric analysis results in a characteristic spectrum, which contains the information related to the chemical composition of the sample under analysis [13, 14]. Since the composition of 
each body fluid is different, it is possible to differentiate each type of body fluid by using these techniques.

In recent years, spectrometric techniques underwent strong development in many different fields. Regarding forensic sciences, spectrometric techniques were used for analysing drugs [15-20] and explosives [15, 21-25] and they are still used at forensic laboratories nowadays. However, approved analyses of body fluids used at forensic institutions have continued unchanged, based on the use of classical chemical assays. Their evolution into modern analytical methods has not happened yet. However, some research groups are investigating and developing novel methods for the analysis of body fluids. Specifically, ultraviolet-visible (UV-Vis), infrared (IR), Raman, X-ray fluorescence $(\mathrm{XRF})$ and nuclear magnetic resonance (NMR) spectroscopy and mass spectrometry (MS) are being investigated in this field.

As common data to all studies, body-fluid stains analysed were all dried stains unless otherwise indicated, in order to test conditions similar to those in real forensic crime scenes, and, for some techniques (e.g. IR spectroscopy), this condition also avoids the problem of the huge IR signals from water.

\section{Ultraviolet-visible spectroscopy}

Illumination with UV-Vis light was the first spectroscopic method used for forensic detection of body fluids. It is based on the two processes that substances subjected to $\mathrm{UV}-\mathrm{Vis}$ radiation may undergo, absorption or fluorescence emission. Under a UV-Vis source, most body fluids (e.g. semen, saliva, and urine) emit fluorescence [26], which is visibly detected as intense brightness of the sample. Blood is not fluorescent at UV-Vis radiation, but it presents a characteristic absorption band in the UV region, which, in good lighting conditions, can create a contrast detectable by the human eye between blood and the background [26].

In 1987, Auvdel [27] first compared the efficiency of using different light sources in the detection of saliva, semen and sweat stains [i.e. monochromatic (argon laser), bichromatic (hand-held Mineralight multiband lamp at UV wavelengths $254 \mathrm{~nm}$ and $366 \mathrm{~nm}$ ) and polychromatic (Fotodyne lamp with UV wavelengths at $254 \mathrm{~nm}$ and 366 $\mathrm{nm}$ and white light of 400-780 nm)]. Stains were prepared at different concentrations 
on sections cut from 23 multicolored clothes made of cotton, cotton-polyester, polyester, polyester-rayon, nylon, nylon-acrylic fiber or acrylic fiber. Different concentrations were obtained by consecutive dilutions (from $1 / 2$ to $1 / 16$ ) of the pure fluids. The argon laser was more efficient than the UV-Vis lamps because it showed better results at detection. Its high intensity allowed detection by visible fluorescence of 17 of 23 semen stains (74\%), 7 of 23 saliva stains (30\%) and 5 of 23 sweat stains (22\%), while the UV-Vis lamps allowed detection of 13 of 23 semen stains (56\%), 5 of 23 saliva stains (22\%) and 4 of 23 sweat stains (17\%). However, a year later, this test was repeated by using a different UV-Vis lamp (Luma-Print, in the wavelength range 400-520 nm) and more favorable results were obtained for the lamp rather than the laser [28]. This UV-Vis lamp allowed detection of 21 of 23 semen stains (91\%), 11 of 23 saliva stains (48\%) and 7 of 23 sweat stains (30\%) - better results than those achieved using the laser. The lamp intensity was enough to produce fluorescence of the stains, and, in comparison to the laser source, a wide range of wavelengths were available. The improvements in UV-Vis lamp manufacture made them more versatile, smaller, lighter and cheaper than UV monochromatic lasers [28].

In 2008, successful results for the detection of body fluids using UV-Vis lamps were also shown by Seidl et al. [29], who compared UV-VIS lamp Lumatec (in the wavelength range 320-700 nm) with a 532-nm laser for detecting blood, semen, saliva and urine stains deposited on glazed tiles, glass, PVC, wood, metal, stone, Formica, carpet and cotton. Comparable results were obtained for the laser and the lamp in the number of semen, saliva and urine stains detected, with the exception that the lamp was more discriminating than the laser. However, the great advantage of the lamp was its capacity to detect blood stains. No blood stain was detected by the 532-nm laser because the absorption band of blood is located at $415 \mathrm{~nm}$. Thus, blood stains were detected by only the lamp [29].

Another UV-Vis lamp successfully used in forensic laboratories for body-fluid detection (Polilight) covers the 310-650-nm region of the electromagnetic spectrum. In 1991, Stoilovic [30] showed its application for locating semen and blood stains placed on different non-photoluminescent and photoluminescent surfaces. In order to overcome the difficulties with respect to the kind of surface, recommended procedures to detect and photograph semen and blood stains were created. Since then, use of this lamp by forensic analysts has spread worldwide. Subsequent studies using the Polilight lamp 
showed instrumental optimizations for the detection of semen stains on fabrics (cotton, wool and polyester) [31] and enhancement in the detection of blood, semen and saliva stains deposited on colored clothes made of cotton, nylon or polyester in comparison to conventional tests based on chemical reagents (luminol, acid phosphatase and amylase tests) [26]. In addition, many other UV-Vis lamps other than Polilight have been developed and used for locating body-fluid stains at crime scenes. The Wood's lamp at $320-400 \mathrm{~nm}$ [32] and the Bluemaxx lamp at 320-510 nm [33] were tested for the detection of semen stains on black and white cotton. Beside semen stains, potential false positive substances were analysed (e.g. bacitracin zinc, barrier cream, hand cream, castile soap, surgilube, toothpaste and A\&D ointment). The results concluded that some of these substances were false positives $[32,33]$.

Finally, the Lumatec lamp at 320-700 nm [34] was studied for the detection of human and boar semen, and human saliva stains on multicolored fabrics made of cotton, polyamide, polyester and spandex. Semen stains were all detected due to their strong fluorescence, while only the $60 \%$ of saliva stains were detected by this lamp. It was demonstrated that the substrate composition did not affect the analysis, but the color did. Dark backgrounds provided the worst results. It was also checked that fluorescence intensity of semen and saliva stains decreased after fabrics were washed [34].

Currently, UV-Vis lamps are known as alternate light sources (ALSs) or forensic light sources, and they are well accepted in the international forensic community as a presumptive and screening test. However, studies reviewed establish that ALSs lack selectivity because fluorescence under UV-Vis radiation is not specific. Fluorescence does not allow confirmation of the body fluid contained in a stain.

In this sense, Powers et al. [35] patented the use of specific light sources (lamps with different bulbs, LEDs and diode lasers) working at different excitation wavelengths to detect the presence of blood, semen, saliva, skin oil and urine stains with the optimum required excitation energies. For this purpose, the excitation wavelengths needed for detecting each body fluid stain were optimized. Table 3 summarizes the results obtained. 
Table 3. Excitation and emission wavelengths for skin oil, semen, blood, urine and saliva. "w" means weak fluorescence. Adapted from [35].

\begin{tabular}{|c|c|c|c|c|c|c|}
\hline Excitation range (nm) & Emission range (nm) & Skin oil & Semen & Blood & Urine & Saliva \\
\hline $250-300$ & $320-360$ & $x$ & $\mathrm{X}$ & $x$ & $\mathrm{X}$ & $x$ \\
\hline $250-300$ & $380-460$ & & & & $X$ & \\
\hline $250-290$ & $430-480$ & & $x$ & & & \\
\hline $360-390$ & $420-510$ & & $X$ & & $X$ & \\
\hline $390-410$ & $430-540$ & & $X$ & & $x$ & \\
\hline $430-470$ & $480-570$ & & $x$ & & $X$ & \\
\hline $520-540$ & $630-700$ & w & & & & w \\
\hline $570-590$ & $630-700$ & & & $x$ & & $X$ \\
\hline $640-680$ & $760-840$ & & & & $X$ & \\
\hline $790-810$ & $860-930$ & & $X$ & & & \\
\hline
\end{tabular}

Regarding the use of lasers for the detection of body fluids traces, though at a lower level, it has not totally disappeared. For example, Soukos et al. [36] used a UV laser at $282 \mathrm{~nm}$ to detect traces of dried saliva on skin after removing them with a cotton swab.

\section{Infrared spectroscopy}

IR radiation has also been applied to the analysis of body fluids. However, its use to study body fluids began two decades ago for clinical purposes [37] and it is later its application to police investigations.

Wang et al. [37] analysed blood drops after drying on a crystal slide by attenuated total reflection (ATR), transmission and diffuse reflection spectroscopy in the wavelength range $500-4000 \mathrm{~cm}^{-1}(20,000-2500 \mathrm{~nm})$, absorbance at $4000-10000 \mathrm{~cm}^{-1}(2500-1000$ $\mathrm{nm}$ ) and photoacoustic spectroscopy at $400 \mathrm{~Hz}$. The principal aim was to test the validity of IR spectroscopy for multicomponent determination in blood and plasma. Results showed water-absorption bands to be problematic, and the utility of IR spectroscopy for qualitative assays but also its limitations for quantitative analysis.

It was not until 2007, when a revolutionary, novel methodology based on the use of IR hyperspectral imaging (HSI) began to be investigated for the forensic analysis of body fluids. HSI combines photography with spectroscopy with the aim of obtaining spectral information of the substances that composed the samples photographed [38]. The spectral information obtained depends on the wavelengths used to photograph the 
sample. To date, there are commercially available HSI systems working in the UV-Vis and IR regions. In comparison to the UV region, the IR region provides more information about the chemical structure of substances. The IR spectrum is unique for each chemical compound and allows unequivocal identification of a substance.

Lin et al. [38] were the first to apply HSI to the forensic analysis of body fluids. For this purpose, they used the near-IR (NIR) region 760-1500 nm and compared with visible light (400-780 nm). This study focused on the analysis of blood stains at different concentrations on black clothes made of different materials, such as cotton, polyester, rayon, velvet, acrylic fiber, wool, lycra and spandex. Different concentrations were prepared by consecutive dilutions (from 1/2 to 1/16) of pure blood. The results obtained showed selectivity and limit of detection (LOD) for NIR better than Vis, specifically for stains on these dark backgrounds. NIR revealed a greater number and more diluted stains than Vis radiation.

Other imaging studies were published using the medium IR region (MIR), 4000-500 $\mathrm{cm}^{-1}$ (2500-20,000 nm). Myrick's team developed a method based on applying the thermal MIR imaging to detect blood stains by studying the contrast observed between the stain and the background [39, 40]. In a first study [39], blood stains prepared at different concentrations on dark acrylic fiber were analysed. Different concentrations were produced by consecutive dilutions (from 1/10 to 1/100) of pure blood. In addition, potential false-positive substances, such as rust, cherry soda and coffee, were analysed and compared with blood stains. Results demonstrated that all blood stains analysed were detected and identified by this method even the most diluted samples (1/100). Results also demonstrated that the potential false positives analysed were not confused with blood, so they were not false positives by this method.

In a second study [40], more diluted blood stains (1/200) and more fabric substrates (cotton, nylon and polyester) were analysed. In addition, the statistical method of principal component analysis (PCA) was applied to data treatment. By PCA, the clean substrate and the blood-stained substrate were successfully differentiated at $95 \%$ confidence.

In another study (reported by Elkins [41]), blood, semen, saliva, vaginal fluid and urine stains deposited on white cotton were first analysed by ATR-FTIR spectroscopy in the MIR region $4000-400 \mathrm{~cm}^{-1}(2500-25,000 \mathrm{~nm})$. One stain per fluid was analysed. In 
order to check false positives, this study also investigated stains of other substances similar in appearance to body fluids by comparing their IR spectra [41]. These substances were barbeque sauce, lotions, mayonnaise, Vaseline, chocolate, coffee, wine, cream cheese, apple juice, ketchup, lipstick and yogurt. This assay also evaluated the effect of temperature $\left(21^{\circ} \mathrm{C}, 40^{\circ} \mathrm{C}\right.$ and $\left.120^{\circ} \mathrm{C}\right)$ in the process of drying the stain. The different FTIR spectra obtained for each body fluid allowed researchers to distinguish between them. Furthermore, the different spectra of body fluids and the substances checked as false positives avoided confusing them. There were no false positives by IR spectroscopy. Regarding the temperature, though its degradation effect reduced the intensity of bands in the spectrum, the variation was insignificant.

Several studies focused on comparing IR and UV-Vis spectroscopy for the analysis of blood stains. De Forest et al. [42] visualized blood stains on dark surfaces by using multispectral imaging in the Vis (RGB LEDs of 400-700 nm) and NIR (850 nm) regions. Four types of blood stain (i.e. smear, contact, drop, and small spatter) were deposited on black fabrics made of cotton, leather, wool, silk and polyester. These four types of blood stain cover those expected at a crime scene. In addition to blood, other substances that may produce false positives were also analysed [e.g. red-pen inks, paints, nail polishes, lipsticks, crayons, "vampire blood" (false blood), ketchup, raspberry jam and wine]. The image analysis involved measuring the luminosity and the color values of the blood stains. The main conclusion was that blood stains on black substrates were better observed by IR radiation, except "small spatter" stains, which were observed by Vis radiation only. Regarding the potential false positive substances, many of them were perfectly distinguishable from blood and only a few were quite similar to blood stains [42].

The same challenging issue in detecting blood stains located on dark surfaces was approached by Finnis et al. [43]. In this case, there was comparison between the potential of photography by UV (at $395 \mathrm{~nm}$ ) and NIR (at 720-900 nm) and traditional chemical assays (e.g. using luminol, hydrogen peroxide and fluorescein tests). For this purpose, blood samples at different concentrations prepared by consecutive dilutions (from 1/10 to 1/106) of pure blood were deposited on several dark substrates made of cotton, leather, rubber, vinyl, wool, polyester and suede. In this case, two types of stain were produced (i.e. drop and small spatter). The results showed the LOD for blood in water solution was about $10 \%(\mathrm{v} / \mathrm{v})$ for NIR photography and the hydrogen-peroxide 
test, $1 \%(\mathrm{v} / \mathrm{v})$ using UV light and $0.1 \%(\mathrm{v} / \mathrm{v})$ for fluorescein and luminol tests. The results also showed that all "drop stains" were detected by all methods. However, IR and UV photography did not detect the "small spatter" stains, while the chemical tests did it.

\section{Raman spectroscopy}

Raman spectroscopy is increasingly used for the analysis of body fluids. First, Raman spectroscopy was applied for the analysis of body fluids, especially blood, for structural and clinical purposes [44, 45]. Venkatesh et al. [44] focused on studying different hemoglobin $(\mathrm{Hb})$ derivatives (oxy-Hb, carbonmonoxy-Hb, met-Hb, deoxy-Hb, hemichrome, $\mathrm{Ni}-\mathrm{Hb}$ ) by Raman spectroscopy in order to obtain structural information, while Enejder et al. [45] analysed blood from 31 individuals by Raman spectroscopy in order to determine and to quantify nine different compounds simultaneously (glucose, urea, cholesterol, total protein, albumin, triglycerides, hematocrit and hemoglobin) for clinical purposes.

However, in the past six years, Raman spectroscopy has been revealed as a promising technique for the forensic analysis of body fluids. The first study focused on the forensic identification of body fluids, especially blood, by Raman spectroscopy was by De Wael et al. [46] In this work, UV-Vis microspectrophotometry at 380-800 nm and FTIR ATR spectroscopy at 4000-400 $\mathrm{cm}^{-1}(2500-25000 \mathrm{~nm})$ were applied together with Raman spectroscopy at 2000-400 $\mathrm{cm}^{-1}(5000-25000 \mathrm{~nm})$ for the identification of blood stains. The blood stains analysed were from three species (human, cat and dog) and were made on clothing, glass slides and a metallic surface. For the blood stains on clothing, small dried particles in the stain were adsorbed on tape to be analysed more easily. The results showed that the three techniques (UV-Vis, IR or Raman) were sensitive enough to allow identification of blood on the basis of its spectrum. However, none of the techniques was able to differentiate the blood of the different species since the UV-Vis, IR and Raman spectra of the three species' blood were visually indistinguishable.

The development of methodologies adapted to the analysis of other body fluids in addition to blood by Raman spectroscopy was mainly tackled by Lednev and his 
research group. In 2008, they published a first study proving the utility of this technique for the identification of blood, semen, saliva, vaginal fluid and sweat [47] and patented it [48]. One dried drop of each body fluid made on a glass slide was analysed by Raman spectroscopy over the range $100-3200 \mathrm{~cm}^{-1}$. The observation that every body fluid presented an intrinsic heterogeneity made it preferable to perform a mapping methodology where Raman spectra at different spots were registered to obtain finally the spectral average of all points. As a result, the Raman spectra of these body fluids were first obtained and are shown in Figure 1.

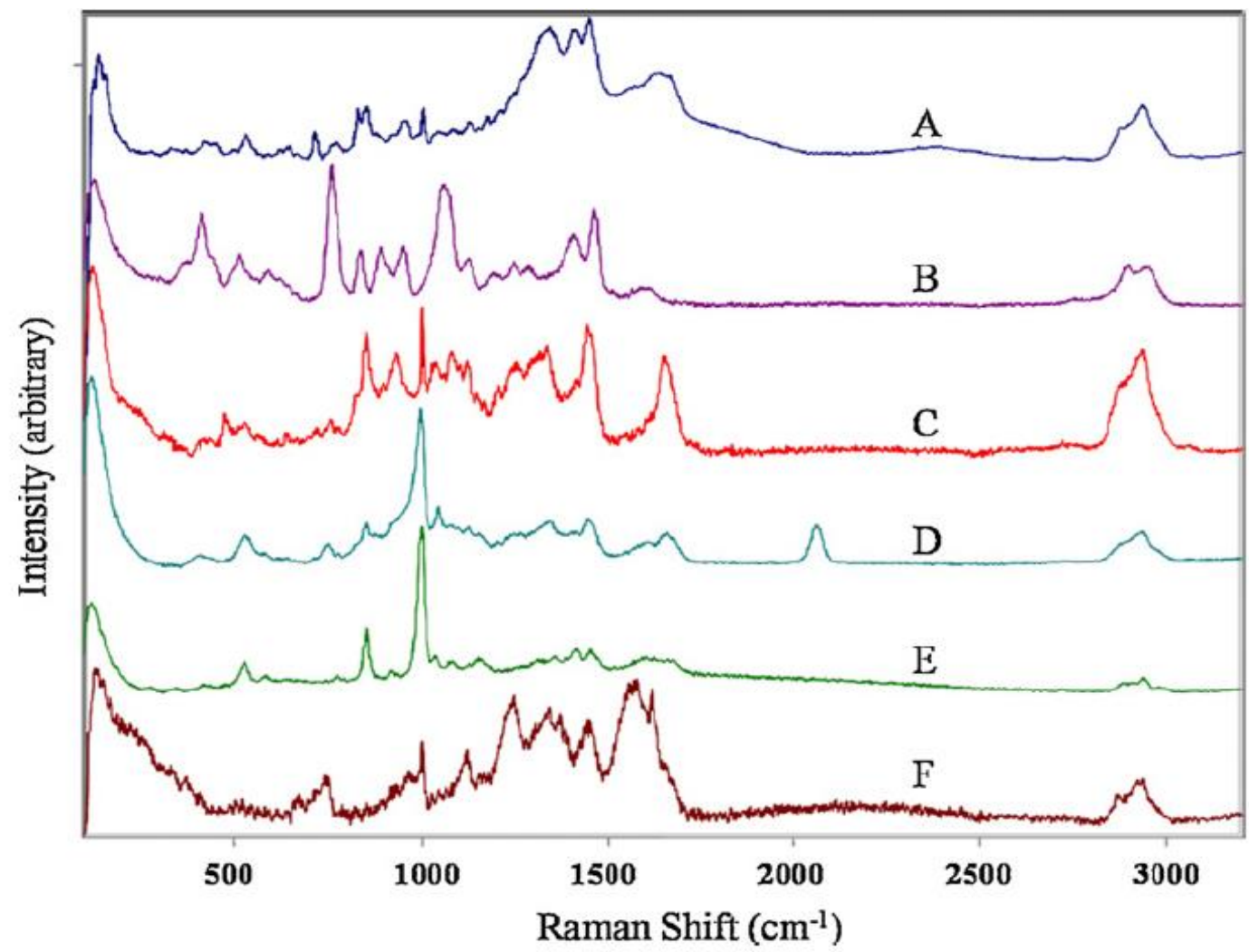

Figure 1. Raman spectra of (A) human semen, (B) canine semen, (C) vaginal fluid, (D) saliva, (E) sweat and (F) blood [47].

Canine semen was also analysed and it was differentiated from human semen by observing the spectral differences at the $500-1500 \mathrm{~cm}^{-1}$ range. In a further step, the Raman bands were assigned to vibrational modes and certain compounds $\{$ e.g. hemoglobin, albumin and glucose were identified in the blood spectrum; albumin, fructose, lysozyme and urea were identified in the semen spectrum; amylase and lipase were identified in the saliva spectrum; lactate, urea, lysozyme, acetate and pyridine were identified in the vaginal fluid spectrum; and, urea was identified in the sweat spectrum $[47,48]\}$. 
Additionally, Virkler and Lednev [49] investigated a problem earlier proposed by De Wael et al. [46] - discrimination among blood stains from human, canine and feline species based on the differences in their Raman spectra. In this study, eight blood samples from each species deposited on glass slides were analysed by Raman spectroscopy at the $250-1800 \mathrm{~cm}^{-1}$ range. A PCA was created to compare the spectra statystically. Contrary to De Wael's conclusion [46], which stated the Raman spectra of the blood of the three species were visually too similar to distinguish them, PCA results indicated that it was possible to discriminate among the bloodstains of the different species under study [49]. Figure 2 shows the Raman spectra of the three blood species analysed and the PCA results obtained.
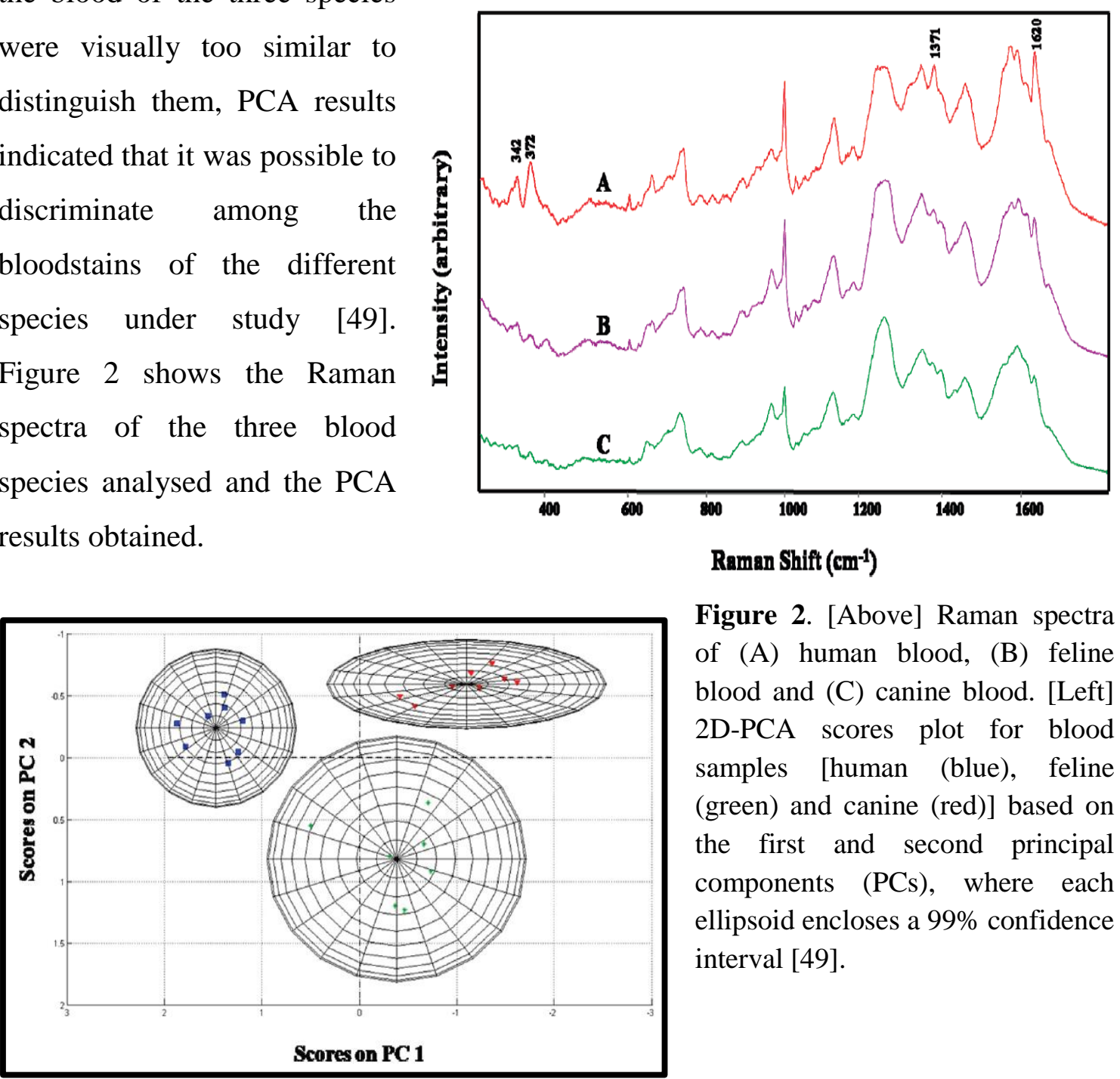

Figure 2. [Above] Raman spectra of (A) human blood, (B) feline blood and (C) canine blood. [Left] 2D-PCA scores plot for blood samples [human (blue), feline (green) and canine (red)] based on the first and second principal components (PCs), where each ellipsoid encloses a 99\% confidence interval [49].

One study related to the analysis of body fluids in sexual abuse cases involved the investigation of condom lubricants as crime evidence. Coyle et al. [50] analysed 47 different condoms in order to identify them by lubricant composition. Samples were taken by cotton swabs from the condoms (before and after use) and from the simulated vaginal vault and pubic area of the victim (immediately before and after sexual 
intercourse). All samples were a mixture among the condom lubricant and body fluids (mainly semen and vaginal fluid). Samples were analysed by Raman spectroscopy at the 200-4000 $\mathrm{cm}^{-1}$ range. To determine the effects of condom lubricants and Raman analysis on DNA from body fluids, the DNA was subjected to genetic analysis. The Raman spectra of samples taken from condoms showed bands that corresponded to polydimethylsiloxane, a known component of lubricants. The Raman spectra of samples taken from the simulated victim also showed those bands, so intercourse was established. Finally, the DNA results indicated that condom lubricants and Raman analysis did not affect to the DNA contained in the body fluids.

Virkler and Lednev continued the investigation of body fluids by establishing statistically the Raman spectroscopic signatures of semen [51], saliva [52] and blood [53]. In these studies, 50 samples of semen, 15 samples of saliva and 14 samples of blood deposited on glass slides were analysed by Raman spectroscopy at the 100-3200 $\mathrm{cm}^{-1}$ range applying a 36-point mapping methodology for semen and saliva samples and a 16-point mapping methodology for blood samples. One each of the semen and blood samples and five of the saliva samples [51-53] were used to get the spectral signatures of semen, saliva and blood, which were fitted to the remaining samples for comparison. The spectral ranges chosen for the Raman signature of each body fluid was 670-1750 $\mathrm{cm}^{-1}$ for semen, $300-1800 \mathrm{~cm}^{-1}$ for saliva and $950-1700 \mathrm{~cm}^{-1}$ for blood. The spectral signatures of the three body fluids were established by applying a significant factor analysis to determine the number of principal components in the spectra of the samples used as standard, and the alternate least squares function to extract the individual component spectra. Spectra fitting was performed using the curvefitting toolbox in MATLAB, and "goodness-of-fit" statistics (sum of squares due to error, R square $\left(\mathrm{R}^{2}\right)$ and root-mean-squared error) were calculated to measure the difference between the fitted spectra and the experimental spectra. The Raman spectral signatures of these body fluids were studied and Raman bands were assigned to certain compounds $\{$ e.g. tyrosine, choline and spermine in semen [51]; mucin, acetate, saccharides and arginine in saliva [52]; and, hemoglobin and fibrin in blood [53]. Moreover, the fitting results showed that all analysed semen, saliva and blood samples presented good results for their spectral signature $\left(\mathrm{R}^{2}>0.98\right)$ and bad fitting results were obtained for the other body fluid signatures [51-53]. 
In order to improve differentiation of these three body fluids, a study, published in 2010 [54], focused on the statistical treatment of Raman spectra measured for the semen, saliva and blood samples analysed [51-53]. To classify these data, different statistical methods were applied \{i.e. SIMCA (Soft Independent Modelling of Class Analogy), LDA (Linear Discriminant Analysis) and PLS-DA (Partial Least Squares Discriminant Analysis) [54]\}. Using these three methods, semen, saliva and blood samples were correctly differentiated. As shown in Figure 3, practically all the experimental data were successfully clustered. The classification of different samples of blood, semen or saliva was also achieved by the three methods. $100 \%$ of the spectra were correctly classified by SIMCA, LDA and PLSDA. The combination of these three methods was a powerful identification and classification tool for blood, semen and saliva samples.

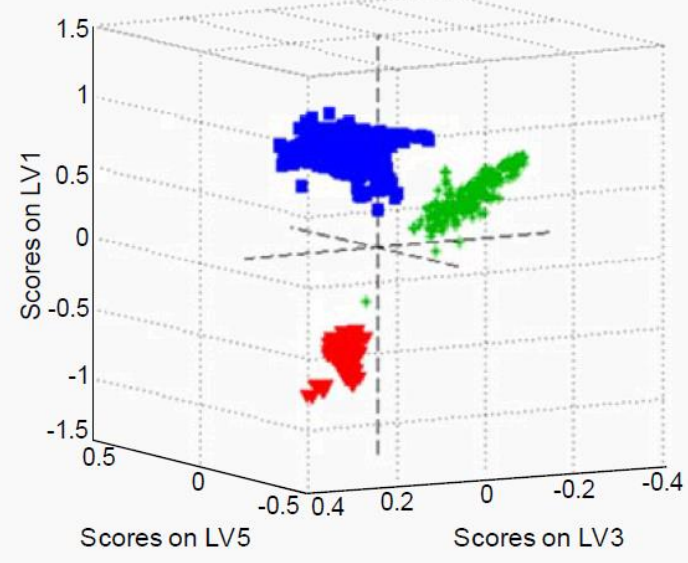

Figure 3. A 3D latent variable (LV) plot of PLS-DA model for samples of blood (red), semen (blue) and saliva (green) based on the first, third and fifth LVs [54].

Regarding blood stains detection by Raman spectroscopy, Boyd et al. [55] amplified the investigation by studying various factors in bloodstains, such as concentration and substrate. In that study, eight blood stains at different concentrations (dilutions from $1 / 50$ to $1 / 500$ ) made on different substrates (e.g. glass slides, denim, flannel, cotton, dry wall and plastics) were analysed by Raman spectroscopy at 400-2000 $\mathrm{cm}^{-1}$. The results of diluted blood stains concluded that the maximum dilution for which at least the most intense blood bands were detectable by Raman spectroscopy was $1 / 250$. The results related to the substrates showed that blood bands were more easily detected in spectra of blood stains on non-luminescent substrates (e.g. glass, wall and plastics). For blood stains on fabrics, spectra were dominated by scattering bands from the fabric and a larger amount of blood was necessary in the stain to make blood bands clearly visible. Thus, an extraction method of blood from fibers was proposed to avoid the analysis of fabrics by Raman spectroscopy. It involved placing a portion of the stained fiber in a centrifuge tube with $500 \mu \mathrm{L}$ of water, flick-mixing it for 1 min and depositing $100 \mu \mathrm{L}$ on a slide. Using this procedure, the contribution of the fabric spectrum was eliminated. 
Lednev's team continued investigation of body fluids by establishing statistically the Raman spectroscopic signatures of vaginal fluid [56] and sweat [57]. In both studies, seven samples of vaginal fluid or sweat deposited on glass slides were analysed by Raman spectroscopy at $100-3200 \mathrm{~cm}^{-1}$ range applying a 117-point mapping methodology for vaginal fluid samples [56] and a 32-point mapping methodology for sweat samples [57]. One of the samples was used to get the spectral signatures of vaginal fluid and sweat, which were fitted to the remaining samples for comparison. The spectral range chosen for the Raman signatures of both body fluids was 300-1800 $\mathrm{cm}^{-1}$. The spectral signatures of these two body fluids were established by applying significant factor analysis to determine the number of principal components for the samples spectra used as standard and the alternate least squares function to extract the spectra of individual components. For spectra comparison and fitting, the same approach previously reported [51-53] was performed, based on the curve fitting toolbox in MATLAB and "goodness-of-fit" statistics. The Raman spectral signatures of both body fluids were subjected to assignment of Raman bands and certain compounds were identified \{e.g. lactic acid, urea and amino acids in vaginal fluid [56] and lactate and urea in sweat [57]\}. In this case, the fitting results showed that all analysed samples of vaginal fluid and sweat presented good results for their spectral signature $\left(R^{2}>0.98\right)$ and bad fitting results for the other body fluid signatures [56, 57].

Once, the spectral signatures of vaginal fluid and sweat were established, it was possible to unify in a single publication the Raman spectroscopic signatures of the five body fluids (blood, semen, saliva, sweat and vaginal fluid) [58]. The five body fluids under study were perfectly differentiated based on their Raman spectral signature. Moreover, it was possible to identify successfully unknown stains by statistical fitting of the corresponding Raman spectra with the specific spectral signature of each body fluid.

With the aim of testing similar conditions to those in real forensic crime scenes, Lednev's team also studied stains containing mixtures of several body fluids; specifically, different mixtures of blood from a woman (potential victim) and sperm from a man (potential attacker) deposited on glass slides were analysed by Raman spectroscopy at the 500-1800 $\mathrm{cm}^{-1}$ range by applying a 108-point mapping methodology [59]. Mixtures were prepared with different blood/semen ratios (5:95, $10: 90,20: 80,30: 70,40: 60,50: 50,70: 30,75: 25,85: 15,87.5: 12.5$, 92.75:6.25, $96.875: 3.125$ and $98.4375: 1.5625)$ by thoroughly shaking for $20 \mathrm{~s}$. 
Statistical treatment based on using Support Vector Machine (SVM) correctly classified the mixture stains in three different groups according to the blood-semen ratio in the mixture (pure blood, pure semen or mixture at 15-75\% blood). Mixtures outside the 15$75 \%$ blood range were not considered like other groups because their spectra were too similar to the spectra of pure semen or pure blood. Results therefore showed that to identify the two body fluids (blood and semen) in a stain properly, it had to have a ratio of $15-75 \%$ blood. Otherwise, it was high probable that it would only register a signal from the main body fluid in the stain.

These types of study were extended by including the potential effects of pollutants, such as sand, dust and soil, in the analysis of bloodstains [60]. Each contaminant was applied to the fresh blood stain on the glass slide so that it completely covered the surface of the fluid. After drying overnight, samples were analysed by Raman spectroscopy at the $300-3200 \mathrm{~cm}^{-1}$ range applying a 108-point mapping methodology. By statistical fitting of the blood signature already established [53] with the experimental spectra, the presence of blood in the stain was determined. In all stains, there were several spots of the 108 measured points that presented a similar Raman spectrum to the blood. In that way, the fitting procedure enabled a PLS-DA classification approach to the identification of nearly pure blood spots within the contaminated stains. Results concluded that a bloodstain can always be identified as blood despite being contaminated or covered with dust, sand and soil.

Lednev wrote a report explaining all the research his group had done in body-fluid identification by Raman spectroscopy and statistical analysis for the US Department of Justice [61]. The main objective was to develop a portable, non-destructive and easy-touse device for identification of body fluids at crime scenes. To reach this aim, Lednev et al. had already obtained the representative, characteristic Raman spectrum of each body fluid (blood, semen, saliva, vaginal fluid and sweat) on glass. They had automatically classified an unknown fluid into the correct category, even in mixtures. They had extended the method developed for stains on glass to other substrates (e.g. cotton, denim or tile). They had also extended the method developed for clean stains to stains contaminated by dust, sand and soil.

Boyd et al. [62] continued the investigation of bloodstains, evaluating the application of surface-enhanced Raman spectroscopy (SERS) technique to the analysis of these stains. 
Blood stains prepared at different concentrations were deposited on different fabrics (denim, flannel and cotton). These samples were analysed by a SERS-active substrate composed of nickel nanotips coated with Ag nanoparticles at the $800-1800 \mathrm{~cm}^{-1}$ range. Results showed that blood was detected by SERS even in a 1/105-diluted blood stain. SERS amplified the blood signal by two orders of magnitude in comparison with conventional Raman spectroscopy. Results also demonstrated that SERS enabled Raman spectra free of substrate fluorescence, even in luminescent substrates, such as fabrics.

Focusing on blood stains, Lednev's team recently approached differentiation between menstrual and peripheral blood using Raman spectroscopy [63]. 21 peripheral blood samples, 20 menstrual blood samples and 8 vaginal fluid samples deposited on glass slides were analysed by Raman spectroscopy in the $625-1730 \mathrm{~cm}^{-1}$ range by applying a 100-point mapping methodology. Band assignment of the spectra obtained revealed that menstrual blood had more compounds than peripheral blood that came from vaginal fluid. Components of menstrual blood were a combination of blood and components of vaginal fluid. PLS-DA and SVM multivariate statistical methods enabled extraction of the statistical information to differentiate and to classify the samples correctly by studying only their Raman spectra. Both statistical methods achieved similar sensitivity and specificity values (>95\%).

The discrimination of human and animal blood stains by Raman spectroscopy was recently re-examined by Lednev's team [64], who included more species and improved the statistical methods used in their previous study [49]. In this later study, they analysed 10 blood samples from 11 different animal species (cow, cat, dog, horse, pig, mouse, opossum, raccoon, rabbit, rat and chicken) besides the human. They analysed samples on glass slides by Raman spectroscopy in the $250-1800 \mathrm{~cm}^{-1}$ range, applying a 35-point mapping methodology. A PLS-DA model enabled them to classify the spectral Raman data of 20 unknown samples correctly [64].

\section{$>X$-rayfluorescence}

The potential of XRF for the forensic detection of body fluids was tested by Trombka et al. [65] in 2002. In that research, gunshot residues (GSRs), blood and semen stains were 
analysed. Since this technique enabled determination of the inorganic composition of samples based on the study of metallic composition, the main goal of this work was to detect blood and semen on the basis of their inorganic composition. For blood samples, the iron present in hemoglobin was followed, while, for sperm samples, the zinc contained in the zinc protoporphyrin enzyme was the element of study. Blood and semen stains were made on filter paper. The presence of $\mathrm{Fe}$ or $\mathrm{Zn}$ in a stain may indicate that those stains are blood and semen, respectively [65].

Three years later, a portable XRF device was designed to enable XRF analysis at crime scenes. By using this portable instrumentation, GSRs, blood and semen stains were detected [66]. Due to this technique focusing on one of the sample components (Fe or $\mathrm{Zn}$ ), it cannot be considered a confirmatory technique because they are not unique to particular body-fluid stains.

\section{Nuclear magnetic resonance}

The use of NMR to analyse body fluids in forensics was introduced recently. Scano et al. [5] were the first to investigate the applicability of $1 \mathrm{H}$ NMR to differentiate among blood, semen, saliva and urine based on their different NMR spectra. 18 samples of blood, 12 samples of semen, 18 samples of saliva and 21 samples of urine were collected and analysed by NMR. Before the analysis, all samples were centrifuged to remove large proteins and solid debris. The supernatant was analysed by NMR after drying and subsequently being reconstituted in $\mathrm{D}_{2} \mathrm{O}$. Binary mixtures $1: 1(\mathrm{v} / \mathrm{v})$ of salivasemen, blood-semen, urine-semen, blood-urine, saliva-urine and blood-saliva were also analysed. The ${ }^{1} \mathrm{H}$ NMR spectra of blood, semen, saliva and urine were then obtained. Based on these spectra, some metabolites, such as propionate, lactate, citrate and several amino acids, were assigned to the spectral bands.

By using a PCA model, it was possible statistically to differentiate these four types of body fluid. As shown in Figure 4, all samples were successfully clustered in four separate groups, in line with the four body fluids. In addition, binary mixtures were situated between the two fluids of their compositions. 


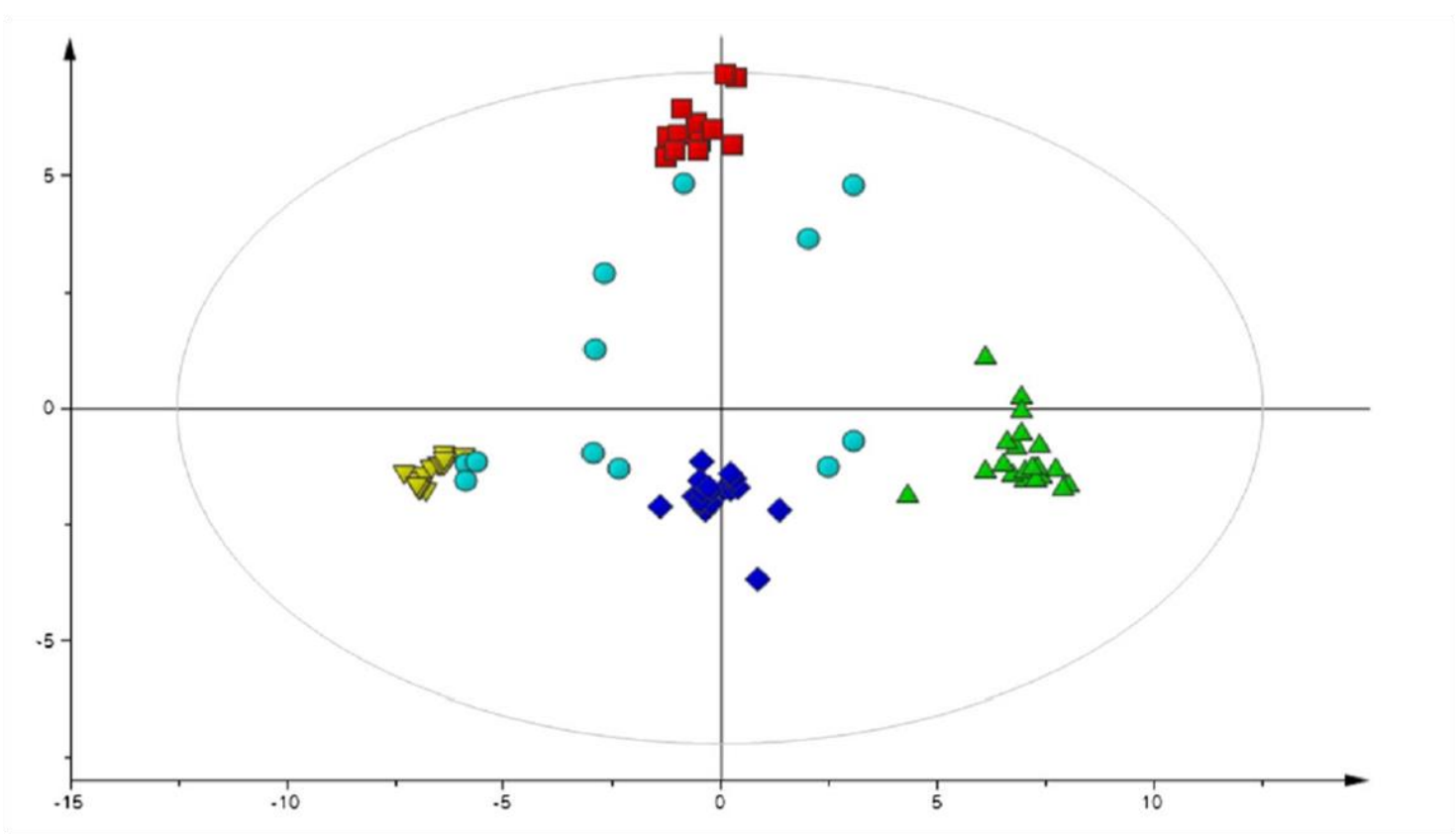

Figure 4. A two-dimensional principal component analysis (PCA) scores plot for samples of blood (yellow inverted triangle), semen (red box), saliva (blue diamond), urine (green triangle) and mixtures (blue circle) based on the first (41\%) and third (14\%) PCs [5].

In a further step, a fitting procedure for body-fluid identification was tested with some of the samples and the binary mixtures analysed. This fitting procedure was based on the average spectral profiles of the four body fluids and the results were reported in terms of root square difference. In this way, the samples tested were correctly identified and the two body fluids were correctly determined in the binary mixtures.

\section{Mass spectrometry}

MS was also recently applied to the analysis of body fluids. Yang et al. [67] applied MS to analyse blood, semen and saliva, and specific proteins present in these body fluids were identified. In this work, instead of analysing RNA, specific proteins were considered as body-fluid markers. Blood, semen and saliva samples at different concentrations were used in two forms: liquid samples or "mock samples" (deposited on cotton swabs). Different dilutions for blood (from 1/10 to $1 / 104$ ), semen (from $1 / 10$ to 1/1000) and saliva (from $1 / 10$ to $1 / 100$ ) were studied. This study included analysis of the aging of body fluids, by analysing the samples over 16 months, and analysis of binary mixtures (i.e. blood-semen, blood-saliva and semen-saliva at different ratios). 
A method based on protein extraction and digestion by chemical reagents, protein separation in a $\mathrm{C} 18$ reversed-phase HPLC column and protein identification by matrixassisted laser desorption/ionization-time of flight spectrometer was used. Samples were also analysed by gel electrophoresis in order to determine the protein amounts in each body fluid. The proteins chosen as markers were $\alpha$ and $\beta$ sub-units of hemoglobin for blood, semenogelin-1 and semenogelin- 2 for semen and $\alpha$-amylase 1 for saliva, among others. MS showed high sensitivity, LOD and specificity values for the identification of blood, semen and saliva based on their specific proteins. MS had the best sensitivity values in comparison with conventional chemical, enzymatic and mRNA profiling methods.

For liquid samples, $0.01 \times 10^{-3} \mu \mathrm{L}$ of blood, $0.1 \times 10^{-3} \mu \mathrm{L}$ of semen and $1 \times 10^{-3} \mu \mathrm{L}$ of saliva were detected by MS. Results also demonstrated that time did not affect the proteins studied. The same results were obtained for the samples throughout the 16 months.

Regarding mixture samples, the main conclusion was that specific proteins of both fluids were always detected by MS with the exception of saliva-blood mixtures with a high proportion of blood where only blood was detected. However, in comparison to the spectroscopic methods, the proposed method is destructive, because it requires a protein-extraction and digestion treatment by chemical reagents, and it is slow because, in addition to the sample-treatment step, it needs a protein HPLC separation for $40 \mathrm{~min}$.

\section{Conclusions and future trends}

Spectrometric techniques are emerging tools for the forensic analysis of body fluids. In the last century, the fluorescence of some body fluids, such as semen and saliva under UV light, was discovered. This discovery has been used by forensic practitioners to detect traces of body fluids.

All studies reviewed based on UV-Vis radiation concluded that it is possible to detect body-fluid stains, but also reported that it is difficult to confirm their presence. This limitation is due to the limited information that UV-Vis and fluorescence emission provides, which is insufficient to differentiate among similar stains. The same applies to 
X-ray fluorescence, which is based on elemental analysis of the body fluid. Because of these limitations, the potential of other spectrometric techniques has been explored in order to analyse and to differentiate between body fluids.

In spite of the high potential of IR spectroscopy for identification of compounds present in samples, it has scarcely been applied in body-fluid samples. Almost all the studies reviewed were focused on analysing blood stains.

In other work, in addition to blood, stains of semen, saliva, vaginal fluid and urine were subjected to preliminary analysis, using only one stain per fluid. Further analyses are needed to establish the IR spectral signature of each body fluid, which is necessary to identify and to characterize them.

The application of Raman spectroscopy to analyse and to differentiate body fluids has been investigated more deeply than has IR spectroscopy, mainly due to the works of the Lednev's team. The Raman spectral signatures of blood, semen, saliva, vaginal fluid and sweat were established by statistical procedures. The identification and the classification of these body fluids were also accomplished by mathematical methods of multivariate analysis. In these works, several stains per fluid and stains from few different donors were analysed.

NMR and MS recently appeared as promising techniques in the investigation of body fluids. Both techniques count on one publication each one where a very complete study reflects the potential of each technique. The NMR study discriminated between blood, semen, saliva and urine by PCA, while the MS study demonstrated its great sensitivity for blood, semen and saliva fluids. However, NMR and MS require sample treatment prior to analysis, which makes them more time-consuming than UV-Vis, IR and Raman spectroscopy.

Other important conclusion extracted from this revision is that modern analytical techniques combined with statistics present a promising future. The most recent studies cited in this review pursue the differentiation of body fluids by the combination between spectrometry and chemometrics.

Therefore, IR spectroscopy, Raman spectroscopy, nuclear magnetic resonance and mass spectrometry have begun to provide successful results for the identification of body fluids when statistical multivariate analyses are performed. Although UV-Vis 
spectroscopy is already a consolidated technique for the presumptive detection of body fluids, none of the other spectrometric techniques reviewed is still being applied as confirmatory analysis by practitioners at forensic laboratories. However, this review shows the evolution of these emerging analytical techniques, mainly IR and Raman spectroscopy, for the forensic analysis of body fluids.

Acknowledgments: F. Zapata and M.A. Fernández de la Ossa thank the University of Alcalá for their pre-doctoral grants.

\section{References}

[1] E. Locard, L'enquête criminelle et les Méthodes scientifiques, 1920.

[2] K. Virkler, I.K. Lednev, Analysis of body fluids for forensic purposes: From laboratory testing to non-destructive rapid confirmatory identification at a crime scene, Forensic Sci. Int. 188 (2009) 1-17.

[3] A.R.W. Jackson, J.M. Jackson, The examination of body fluids, in: A.R.W. Jackson, J.M. Jackson, Forensic Science, Pearson Prentice Hall, Harlow, England, 2008, pp. 115136.

[4] R. Li, Forensic Serology, in: L. Kobilinsky, Forensic Chemistry Handbook, Wiley, New Jersey, 2012, pp. 269-290.

[5] P. Scano, E. Locci, A. Noto, G. Navarra, F. Murgia, M. Lussu, L. Barberini, L. Atzori, F. De Giorgio, M.F. Rosa, E. d'Aloja, ${ }^{1}$ H NMR metabolite fingerprinting as a new tool for body fluid identification in forensic science, Magn. Reson. Chem. 51 (2013) 454462.

[6] M. Bauer, RNA in forensic science, Forensic Sci. Int. Gen. 1 (2007) 69-74.

[7] J. Juusola, J. Ballantyne, Messenger RNA profiling: A prototype method to supplant conventional methods for body fluid identification, Forensic Sci. Int. 135 (2003) 85-96.

[8] C. Haas, B. Klesser, A. Kratzer, W. Bär, mRNA profiling for body fluid identification, Forensic Sci. Int. Genet. Suppl. Series 1 (2008) 37-38. 
[9] J.H. An, K. Shin, W.I. Yang, H.Y. Lee, Body fluid identification in forensics, BMB Rep. 45 (2012) 545-553.

[10] K. Watanabe, Y. Iwashima, T. Akutsu, K. Sekiguchi, K. Sakurada, Evaluation of a coextraction method for real-time PCR-based body identification and DNA typing, Leg. Med. 16 (2014) 56-59.

[11] J. Juusola, J. Ballantyne, Multiplex mRNA profiling for the identification of body fluids, Forensic Sci. Int. 152 (2005) 1-12.

[12] R.I. Fleming, S.A. Harbison, The development of a mRNA multiplex RT-PCR assay for the definitive identification of body fluids, Forensic Sci. Int. Gen. 4 (2010) 244-256.

[13] S. Bell, Instrumentation, in: S. Bell, Forensic Chemistry, Pearson, New Jersey, 2006, pp. 132-211.

[14] A. Koçak, The Role of Vibrational Spectroscopy in Forensic Chemistry, in: L. Kobilinsky, Forensic Chemistry Handbook, Wiley, New Jersey, 2012, pp. 251-268.

[15] N.N. Daéid, Review Papers, 17th INTERPOL International Forensic Science Managers Symposium, Lyon, France (2013), 280-610.

[16] F.P. Smith, Handbook of Forensic Drug Analysis, Elsevier, 2005.

[17] D.E. Bugay, Characterization of the solid-state: spectroscopic techniques, Adv. Drug Deliver. Rev. 48 (2001) 43-65.

[18] A.G. Ryder, G.M. O'Connor, T.J. Glynn, Identifications and Quantitative Measurements of Narcotics in Solid Mixtures Using Near-IR Raman Spectroscopy and Multivariate Analysis, J. Forensic Sci. 44 (1999) 1013-1019.

[19] M.L. Smith, S.P. Vorce, J.M. Holler, E. Shimomura, J. Magluilo, A.J. Jacobs, M.A. Huestis, Modern Instrumental Methods in Forensic Toxicology, J. Anal. Toxicol. 31 (2007) 237-253.

[20] H.R.H. Ali, Non-invasive in situ identification and band assignments of diazepam, flunitrazepam and methadone hydrochloride with FT-near-infrared spectroscopy, Forensic Sci. Int. 206 (2011) 87-91.

[21] J. Yinon, Counterterrorist Detection Techniques of Explosives, Elsevier, Amsterdam, The Netherlands, 2007, pp. 41-366. 
[22] J.I. Steinfeld, J. Wormhoudt, Explosives Detection: A Challenge for Physical Chemistry, Annu. Rev. Phys. Chem. 49 (1998) 203-232.

[23] D.S. Moore, Instrumentation for trace detection of high explosives, Rev. Sci. Instrum. 75 (2004) 2499-2512.

[24] S. Wallin, A. Pettersson, H. Östmark, A. Hobro, Laser-based standoff detection of explosives: a critical review, Anal. Bioanal. Chem. 395 (2009) 259-274.

[25] J.S. Caygill, F. Davis, S.P.J. Higson, Current trends in explosive detection techniques, Talanta 88 (2012) 14-29.

[26] N. Vandenberg, R.A.H. van Oorschot, The Use of Polilight in the Detection of Seminal Fluid, Saliva, and Bloodstains and Comparison with Conventional Chemical-Based Screening Tests, J. Forensic Sci. 51 (2006) 361-370.

[27] M.J. Auvdel, Comparison of Laser and Ultraviolet Techniques Used in the Detection of Body Secretions, J. Forensic Sci. 32 (1987) 326-345.

[28] M.J. Auvdel, Comparison of Laser and High-Intensity Quartz Arc Tubes in the Detection of Body Secretions, J. Forensic Sci. 33 (1988) 929-945.

[29] S. Seidl, R. Hausmann, P. Betz, Comparison of laser and mercury-arc lamp for the detection of body fluids on different substrates, Int. J. Legal Med. 122 (2008) 241-244.

[30] M. Stoilovic, Detection of semen and blood stains using polilight as a light source, Forensic Sci. Int. 51 (1991) 289-296.

[31] H.J. Kobus, E. Silenieks, J. Scharnberg, Improving the Effectiveness of Fluorescence for the Detection of Semen Stains on Fabrics, J. Forensic Sci. 47 (2002) 819-823.

[32] K.A. Santucci, D.G. Nelson, K.K. McQuillen, S.J. Duffy, J.G. Linakis, Wood's Lamp Utility in the Identification of Semen, Pediatrics 104 (1999) 1342-1344.

[33] D.G. Nelson, K.A. Santucci, An Alternate Light Source to Detect Semen, Acad. Emerg. Med. 9 (2002) 1045-1048.

[34] A. Fiedler, J. Rehdorf, F. Hilbers, L. Johrdan, C. Stribl, M. Benecke, Detection of Semen (Human and Boar) and Saliva on Fabrics by a Very High Powered UV-/VISLight Source, Open Forensic Sci. J. 1 (2008) 12-15.

[35] L.S. Powers, C.R. Lloyd, Method and apparatus for detecting and imaging the presence of biological materials, U.S. Patent documents, 2007. 
[36] N.S. Soukos, K. Crowley, M.P. Bamberg, R. Gillies, A.G. Doukas, R. Evans, N. Kollias, A rapid method to detect dried saliva stains swabbed from human skin using fluorescence spectroscopy, Forensic Sci. Int. 114 (2000) 133-138.

[37] J. Wang, M. Sowa, H.H. Mantsch, A. Bittner, H.M. Heise, Comparison of different infrared measurement techniques in the clinical analysis of biofluids, Trends Anal. Chem. 15 (1996) 286-296.

[38] A.C. Lin, H. Hsieh, L. Tsai, A. Linacre, J.C. Lee, Forensic Applications of Infrared Imaging for the Detection and Recording of Latent Evidence, J. Forensic Sci. 52 (2007) 1148-1150.

[39] H. Brooke, M.R. Baranowski, J.N. McCutcheon, S.L. Morgan, M.L. Myrick, Multimode Imaging in the Thermal Infrared for Chemical Contrast Enhancement. Part 3: Visualizing Blood on Fabrics, Anal. Chem. 82 (2010) 8427-8431.

[40] S.L. Morgan, M.L. Myrick, Rapid Visualization of Biological Fluids at Crime Scenes using Optical Spectroscopy, Report to the U.S. Department of Justice, 2011.

[41] K.M. Elkins, Rapid Presumptive "Fingerprinting" of Body Fluids and Materials by ATR FT-IR Spectroscopy, J. Forensic Sci. 56 (2011) 1580-1587.

[42] P.R. De Forest, R. Bucht, F. Kammerman, B. Weinger, L. Gunderson, Blood on BlackEnhanced Visualization of Bloodstains on Dark Surfaces, Report to the U.S. Department of Justice, 2009.

[43] J. Finnis, J. Lewis, A. Davidson, Comparison of methods for visualizing blood on dark surfaces, Sci. Justice 53 (2013) 178-186.

[44] B. Venkatesh, S. Ramasamy, M. Mylrajan, R. Asokan, P.T. Manoharan, J.M. Rifkind, Fourier transform Raman approach to structural correlation in hemoglobin derivatives, Spectrochim. Acta A 55 (1999) 1691-1697.

[45] A.M.K. Enejder, T. Koo, J. Oh, M. Hunter, S. Sasic, M.S. Feld, G.L. Horowitz, Blood analysis by Raman spectroscopy, Opt. Lett. 27 (2002) 2004-2006.

[46] K. De Wael, L. Lepot, F. Gason, B. Gilbert, In search of blood - Detection of minute particles using spectroscopic methods, Forensic Sci. Int. 180 (2008) 37-42.

[47] K. Virkler, I.K. Lednev, Raman spectroscopy offers great potential for the nondestructive confirmatory identification of body fluids, Forensic Sci. Int. 181 (2008) e1-e5. 
[48] I.K. Lednev, K. Virkler, Identification of body fluids using Raman spectroscopy, U.S. Patent documents, 2009.

[49] K. Virkler, I.K. Lednev, Blood Species Identification for Forensic Purposes Using Raman Spectroscopy Combined with Advanced Statistical Analysis, Anal. Chem. 81 (2009) 7773-7777.

[50] T. Coyle, N. Anwar, A novel approach to condom lubricant analysis: In-situ analysis of swabs by FT-Raman Spectroscopy and its effects on DNA analysis, Sci. Justice 49 (2009) 32-40.

[51] K. Virkler, I.K. Lednev, Raman spectroscopic signature of semen and its potential application to forensic body fluid identification, Forensic Sci. Int. 193 (2009) 56-62.

[52] K. Virkler, I.K. Lednev, Forensic body fluid identification: The Raman spectroscopic signature of saliva, Analyst 135 (2010) 512-517.

[53] K. Virkler, I.K. Lednev, Raman spectroscopic signature of blood and its potential application to forensic body fluid identification, Anal. Bioanal. Chem. 396 (2010) 525534.

[54] V. Sikirzhytski, K. Virkler, I.K. Lednev, Discriminant Analysis of Raman Spectra for Body Fluid Identification for Forensic Purposes, Sensors 10 (2010) 2869-2884.

[55] S. Boyd, M.F. Bertino, S.J. Seashols, Raman spectroscopy of blood samples for forensic applications, Forensic Sci. Int. 208 (2011) 124-128.

[56] A. Sikirzhytskaya, V. Sikirzhytski, I.K. Lednev, Raman spectroscopic signature of vaginal fluid and its potential application in forensic body fluid identification, Forensic Sci. Int. 216 (2012) 44-48.

[57] V. Sikirzhytski, A. Sikirzhytskaya, I.K. Lednev, Multidimensional Raman spectroscopic signature of sweat and its potential application to forensic body fluid identification, Anal. Chim. Acta 718 (2012) 78-83.

[58] V. Sikirzhytski, A. Sikirzhytskaya, I.K. Lednev, Multidimensional Raman Spectroscopic Signatures as a Tool for Forensic Identification of Body Fluid Traces: A Review, Appl. Spectrosc. 65 (2011) 1223-1232.

[59] V. Sikirzhytski, A. Sikirzhytskaya, I.K. Lednev, Advanced statistical analysis of Raman spectroscopic data for the identification of body fluid traces: Semen and blood mixtures, Forensic Sci. Int. 222 (2012) 259-265. 
[60] A. Sikirzhytskaya, V. Sikirzhytski, G. McLaughlin, I.K. Lednev, Forensic Identification of Blood in the Presence of Contaminations Using Raman Microspectroscopy Coupled with Advanced Statistics: Effect of Sand, Dust, and Soil, J. Forensic Sci. 58 (2013) 1141-1148.

[61] I.K. Lednev, Application of Raman Spectroscopy for an Easy-to-Use, on-Field, Rapid, Nondestructive, Confirmatory Identification of Body Fluids, Report to the U.S. Department of Justice, 2012.

[62] S. Boyd, M.F. Bertino, D. Ye, L.S. White, S.J. Seashols, Highly Sensitive Detection of Blood by Surface Enhanced Raman Scattering, J. Forensic Sci. 58 (2013) 753-756.

[63] A. Sikirzhytskaya, V. Sikirzhytski, I.K. Lednev, Raman spectroscopy coupled with advanced statistics for differentiating menstrual and peripheral blood, J. Biophotonics 7 (2014) 59-67.

[64] G. McLaughlin, K.C. Doty, I.K. Lednev, Discrimination of human and animal blood traces via Raman spectroscopy, Forensic Sci. Int. 238 (2014) 91-95.

[65] J.I. Trombka, J. Schweitzer, C. Selavka, M. Dale, N. Gahn, S. Floyd, J. Marie, M. Hobson, J. Zeosky, K. Martin, T. McClannahan, P. Solomon, E. Gottschang, Crime scene investigations using portable, non-destructive space exploration technology, Forensic Sci. Int. 129 (2002) 1-9.

[66] J.S. Schweitzer, J.I. Trombka, S. Floyd, C. Selavka, G. Zeosky, N. Gahn, T. McClanahan, T. Burbine, Portable generator-based XRF instrument for non-destructive analysis at crime scenes, Nucl. Instrum. Meth. B 241 (2005) 816-819.

[67] H. Yang, B. Zhou, H. Deng, M. Prinz, D. Siegel, Body fluid identification by mass spectrometry, Int. J. Legal Med. 127 (2013) 1065-1077. 